\title{
METHODS AND TECHNIQUES OF PERCUTA- NEOUS EXTERNAL FIXATION IN PELVIC FRACTURES
}

\author{
Pavlin Apostolov, Martin Burnev, Petar Milkov \\ Clinic of Orthopaedics and Traumatology \\ MBAL "Saint Anna" Hospital - Varna, Bulgaria
}

\begin{abstract}
The authors make a review and present their experience with the use of percutaneous external fixation techniques in pelvic fractures: (1) Transiliac placement (classic method - through the wings of the iliac bone, behind anterior superior iliac spine); (2) Sub-Iliac Crest technique (beneath and along the length of iliac crests); (3) Supra-acetabular Method (Frontal, antero-inferior). They review as well different variants of half-pin placement techniques and analyze the final results of external pelvic fixation study including 65 patients for 10 -year period. The authors recommend more frequently usage of anteroinferior technique (supra-acetabular). According to them, this method exceeds the other techniques by many criteria.
\end{abstract}

Key words: Pelvic Fractures; Percutaneous Fixation; Half-pin placement techniques

\section{INTRODUCTION:}

The beginning of the external fixation, as such, was more than 100 years ago. It has been used in the treatment of unstable pelvic injuries for more than 50 years now. Its role in the emergency treatment of these injuries is based on its ability to set and stabilize the fractured fragments. Riemer et al. demonstrate a decrease in mortality rates from $26 \%$ to $6 \%$. Latenser et al. ${ }^{4}$ compare the use of early external stabilization to the lack of such in the treatment of unstable pelvic fractures. The group with external fixation shows a shorter hospital stay, decreased mortality (from $17 \%$ to $0 \%$ ) and morbidity, minor systematic complications, and decreased consumption of blood products.

External fixation stability depends on the type of the fracture, the patient's habitus, the bone quality, the design of the fixator, the number and size of the pins, the reduction quality, the technique of maintenance, etc.

Actually, the success of the anterior fixation is, above all, a function of the condition of the posterior pelvic complex.

\section{METHODS:}

Methods of external stabilization of pelvic injuries:

1. Non-invasive techniques (special manufactured devises (belts); bandages; bed sheets; vacuum splints; Gsuit; MAST)

2. Invasive techniques

- Anterior external fixation (with/without skeletal traction)

- through the iliac wings ("upper way") (Slatis)

- supra-acetabular ("lower way")

- sub-crystal

- Posterior external fixation (with/without skeletal traction)

- C-clamp

Anterior external fixation through the iliac wings (anterosuperior technique, "upper way")

Because of anatomical considerations, the entry hole for the half-pins is on the borderline between the internal and middle third of the bone width. In acute cases, percutaneous technique is preferred and two pins are inserted at each side. In case that there is more time, three pins are inserted to ensure better stability of the frame. The pins are at least $1 \mathrm{~cm}$ apart. The insertion direction is usually $45^{\circ}$ to the surgery table but sometimes this is determined individually. Pins with $5 \mathrm{~mm}$ diameter are usually used (4 to 6). The procedure is not always as simple as it may seem, especially with obesity patients. To ensure the pin insertion direction, we can slide one Kirshner pin along the internal cortex of the iliac bone and another along the external cortex of the iliac bone, so that the bisector between them to give us the direction of insertion. The solidity of the placement is checked manually and radiologically and then the frame is assembled, in a way that it leaves place to work on the abdomen. 


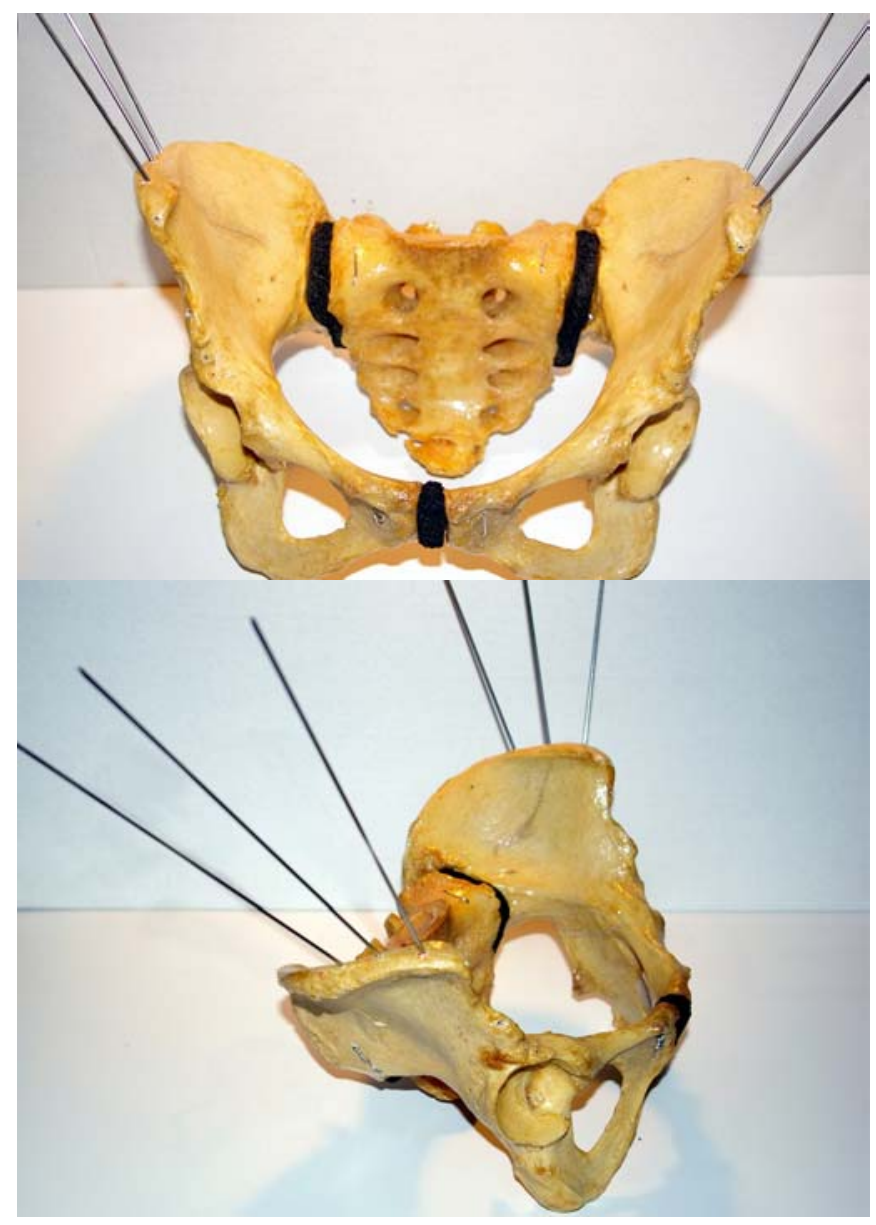

Fig. 1-a, 1-b.

With open book injuries (Tile B1), the anterior compression alone will suffice. For B2 (bucket handle, with lateral compression) injuries, external rotation of the compressed wing is necessary. For total instability (Tile C), besides the anterior fixation, some type of posterior fixation or traction is also necessary.

\section{Supra- acetabular exterior fixation (anterior, antero- inferior, "lower way")}

The bone above acetabulum is solid and that ensures the tight grip of the pin. Biomechanical studies have proved that, placed this way, the same fixator gives better stability in the region of SI joints than placed the "upper way" (Kim WY, Hearn TC, Seleem O, Egberg HY, Drajher F, Haveman D. et al. ${ }^{5,6}$ Some author warn that, if there is a lack of sufficient experience, this way may have some serious risks 7,8 (penetration into the hip joint, injury to the neurovascular structures in the great incisure's region), while others use it in cases of emergency and percutaneously (Pohlemann T., Regel G., Bosch U., etc. ${ }^{9}$ ). Over the last few years we have been working excessively this way (with X-ray) and we recommend it as better than the others, as, in our opinion, it combines three crucial qualities - safety, simplicity, and effectiveness.

This method exceeds the most wildly used variant "upper way", since it is easier to close a book from the front than the top. ${ }^{10}$

In our opinion, the advantages of supra-acetabular technique are as follows:

- Firmer pin anchorage to the bone (tighter spongiosis)

- Greater insertion depth

- Bigger diameter $(6 \mathrm{~mm}$ ) of the pins (4 or $5 \mathrm{~mm}$ in anterior-superior technique)

- More even distribution of the weigh over the SI joints

- Greater stability in the posterior pelvic ring

- Lower risk of penetration

- Lower risk of infection

- Bigger freedom in abdomen operations

- More comfortable for the patient (when sitting down)

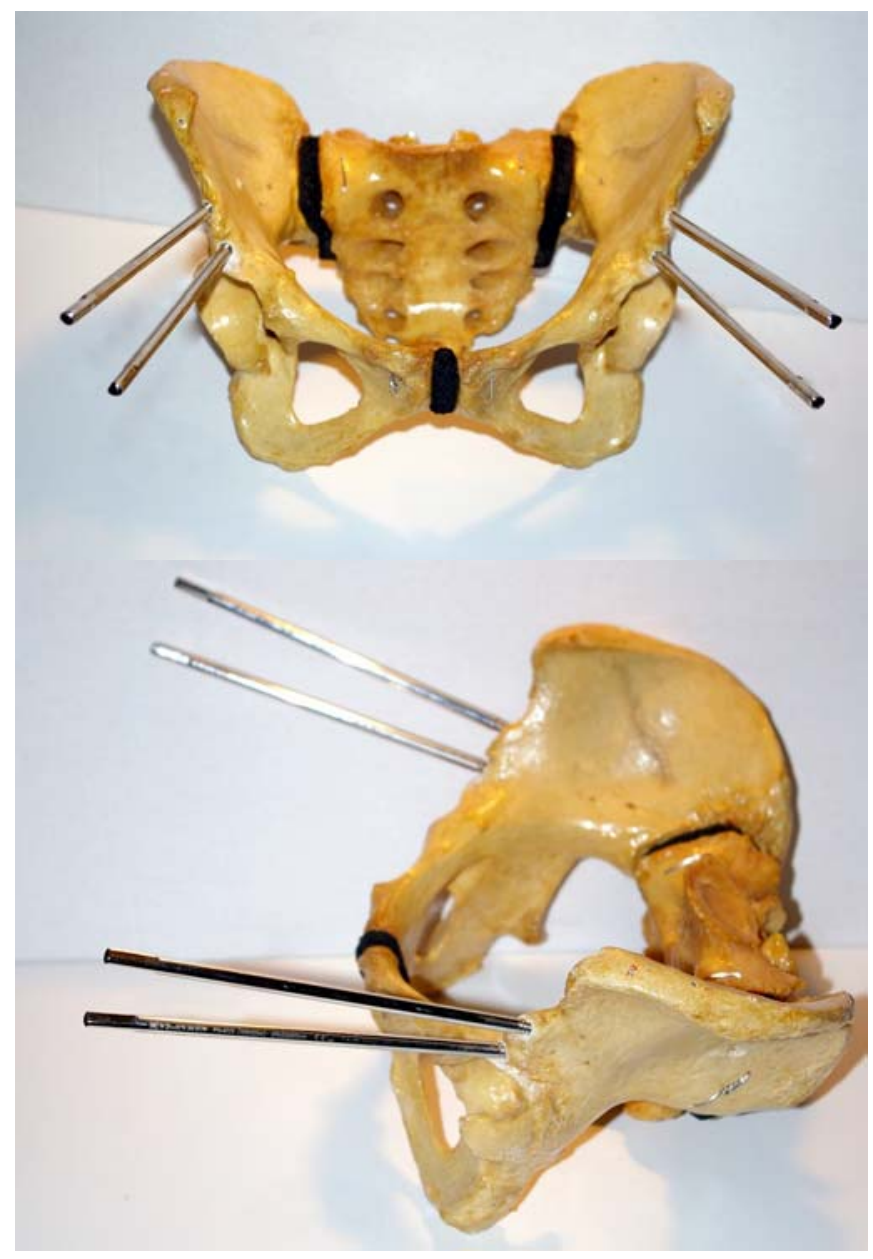

Fig. 2-a, 2-b.

\section{Subcrystal technique}

This is a more recent method, which has been 
developed as an alternative to anterosuperior (Slatis) and anteroinferior (supra-acetabular) techniques of placing the external fixator. It was developed by Solomon LB et al. and published in February 2009. ${ }^{11}$ This is the easiest of the three techniques, with the fewest possibilities for mistakes at placement and the fewest complications, and even a nonspecialist in the pelvic and acetabular surgery can apply it. The whole procedure is approximately 10 minutes long.

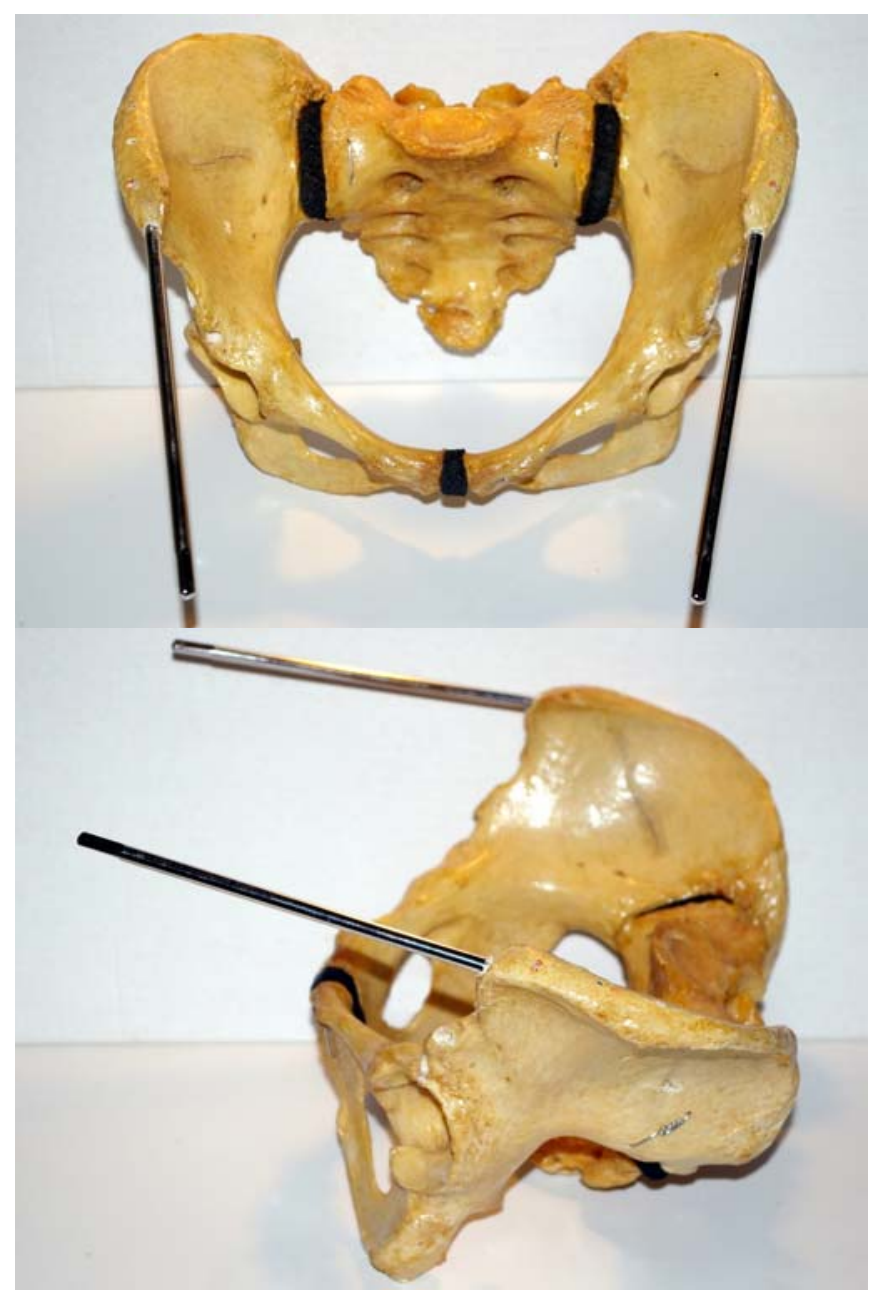

Figures 3-a, 3-b

Another advantage of this technique is that practically there are no crucial anatomic structures here, that can be injured (n.cutaneus.fem.lat. lies beneath lig.inguinale, or goes through it). The accurate placement of the pins in an anterosuperior technique can be rather difficult if there is a lack of sufficient experience, and some authors (Waikakul et al. ${ }^{12}$ ) report $18 \%$ incorrect placements. Supra-acetabular placement also requires previous experience, because of the thicker layer of soft tissue between the skin and the bone.

\section{Posterior Exterior Fixation - C-clamp}

There were some publications in the German literature in 1964 and 1972 in regard to the use of devises similar to the C-clamp, but their modern era begins with the report of Ganz et al. in 1991 and Buckle et al. in 1994 ${ }^{13,14}$.

Biomechanical studies has shown that the C-clamp provides better fixation than any other pelvic fixator does, when the posterior instable pelvic injuries are concerned. It improves the conditions for an effective hemostasis by compressing fracture surfaces, eliminating motion and dislodgement of previously formed clots, decreasing the pelvic volume. This way the so-called self-tamponade is enhanced, and a firm support is provided in case a tamponage is necessary. Many patients immediately show improvements in the vital signs after the application of the clamp ${ }^{15}$.

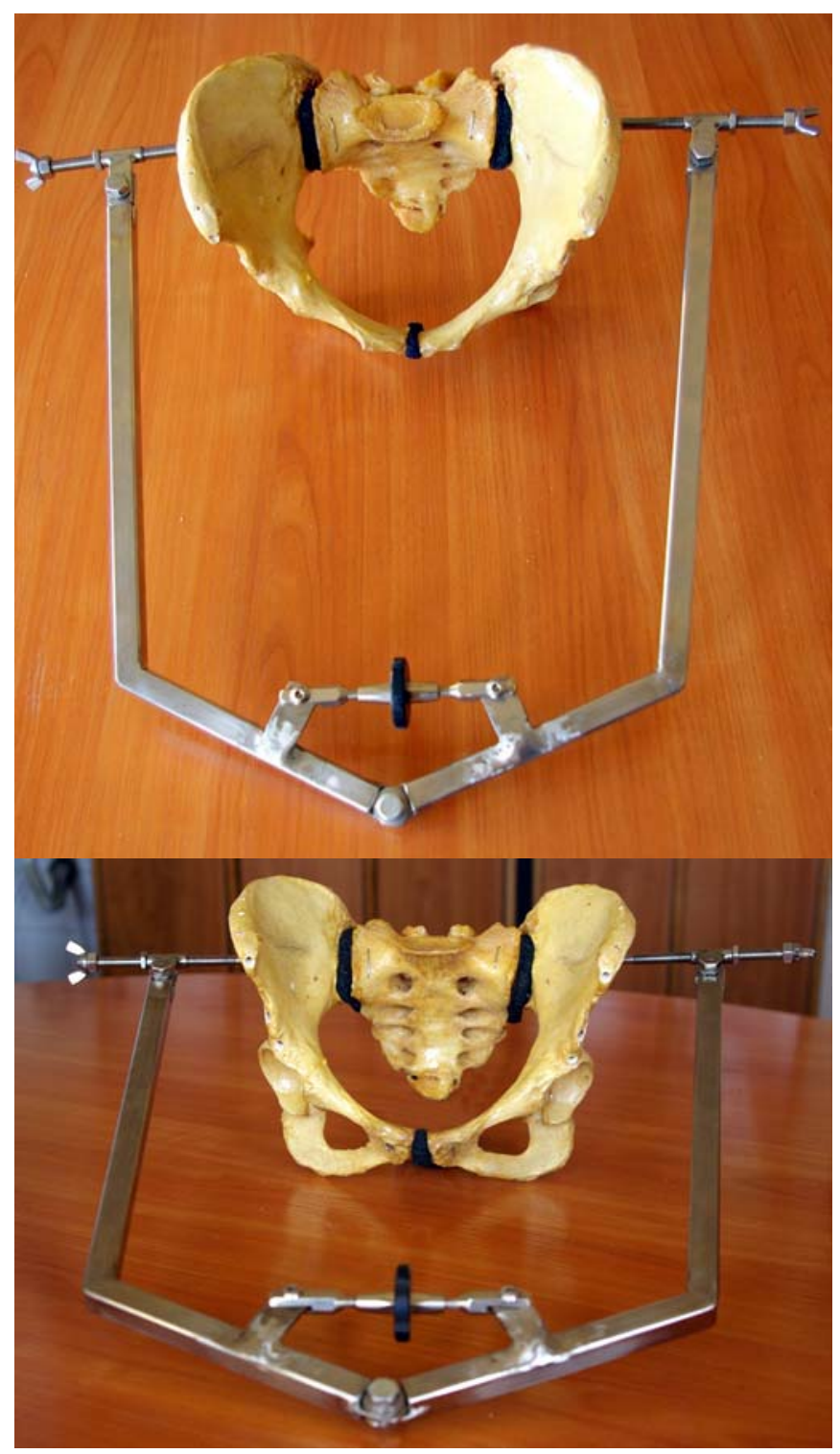

Figure 4-a, 4-b 
The technique of placing the C-clamp is standard, but we used our C-clamp, developed in cooperation with KMUniconsult, Varna. Anatomic reposition is not aimed at, but what is important is the pelvis to be "closed", compressed, and stabilized. This dramatically limits the pelvic hemorrhage and is a life-saving manipulation. The accurate reduction and the definitive fixation are maintained after stabilizing the general condition of the patient.

\section{MATERIALS:}

There were 396 patients with pelvic injuries in the Clinic of Orthopaedics and Traumatology at MBAL St Anna Hospital, Varna from June 2000 to June 2009. Of these, 89 were operated and the external fixation was applied (solely or combined) to 65 patients. Different techniques of external fixation were used and the most common of them (with 41 cases) was the supra-acetabular variant.

\section{Graph 1}

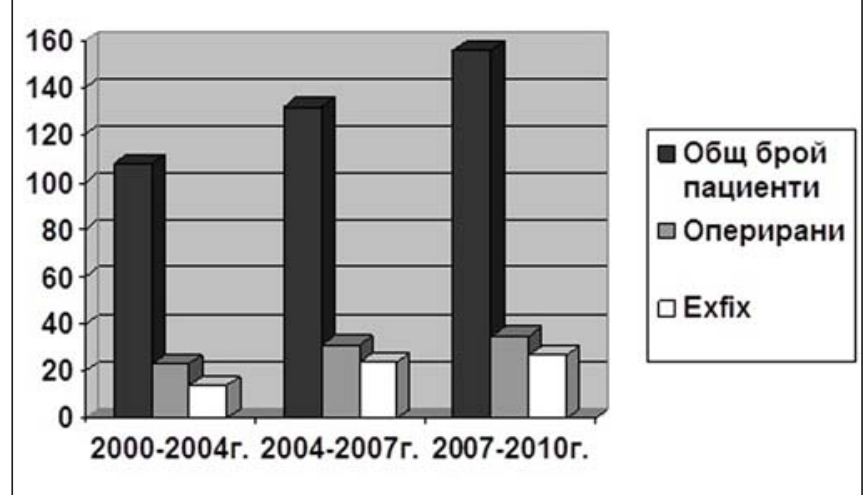

The distribution of the patients according to the type of external fixation is as follows:

- Through the iliac wings - 18 cases

- Supra-acetabular - 41 cases

- Combination of the two - 4 cases

- Subcristal - 2 cases

- C-clamp - 7 cases

The types of fixation with all pelvic injuries are:

- External fixation only $=46$

- External and internal fixation (hybrid) $=14$

- External fixation and traction $=5$

- Internal fixation only $=24$

\section{RESULTS:}

The injuries were classified by Tile and were respectively $70.76 \%$ of type B (46 patients) and $29.24 \%$ of type C (19 patients) of those operated with external fixation. The evaluation of the results is done on Majeed's scheme, modified by us, and they are as follows:

Table 1

\begin{tabular}{|c|c|c|}
\hline Results in the $18^{\text {th }}$ month & Number of patients: & In percentages \\
\hline Excellent & 34 & 52.3 \\
\hline Good & 17 & 26.2 \\
\hline Satisfactory & 8 & 12.3 \\
\hline Poor & 6 & 9.2 \\
\hline
\end{tabular}

If we examine injuries Type $\mathrm{B}$ and $\mathrm{C}$ in detailes:

Table 2

\begin{tabular}{|l|c|c|c|c|}
\hline Injury: & Excellent result: & Good result: & Satisfactory result: & Poor result: \\
\hline B-type & 28 & 14 & 2 & 2 \\
\hline C-type & 6 & 3 & 6 & 4 \\
\hline Total & 34 & 17 & 8 & 6 \\
\hline
\end{tabular}

From the total number of examined patients (65), there were 46 (70.76\%) with type-B injury and 19 (29.24\%) with typeC injury. 
Table 3.

Type-B - Excellent + Good $=42$ patients $(91.3 \%)$

Type-C - Excellent + Good $=9$ patients $(47.36 \%)$

Type-B - Poor $=2$ patients $(4.3 \%)$

Type-C - Poor $=4$ patients $(21 \%)$

\section{DISCUSSION:}

The following considerations must be taken into account, in order to select the adequate construction of the fixator. Simple configurations in cases of emergency will suffice and are done to "close" the shattered pelvic ring. If a laparotomy becomes necessary, the fixation should not hinder it. The stability and maneuverability depend on the position of the pins. They can be placed in the iliac wings, ventrally in the supra-acetabular region, laterally - above the acetabulum, sub-crystal, etc. They can also be inserted into the pubis bones, but this procedure is only relevant in the case of a definitive treatment. Since the pins are the weak point regarding stability during exercise, their number and diameter are especially crucial. The connection between the pins, as well as the main connecting bar of the frame, should be as close to the skin as possible. In order to prevent an infection, it is recommendable to clean the pins daily with $0.9 \%$ saline solution or with antiseptic solutions that do not irritate the skin. Regardless of the bulky looking appearance of some constructions, the mechanical stability of the external fixator should not be overestimated. Even relatively small loads can result in secondary dislocation, especially in the conjunctions, which tend to loosen over time. Regular X-rays and $\mathrm{CT}$ controls are necessary to detect possible changes, which can be an indexation for corrections or a secondary reduction. The probability of an additional surgical treatment and a change of the procedure plan grow bigger with the instability of the fracture itself.

The application of a pelvic fixator has its natural limits. Naturally, complex constructions are able to take more loads, but they also require more space. Consequently, they cannot be used in emergencies and with severely injured patients as they are a hindrance to some manipulations in the abdomen. However, these disadvantages are already avoided with most contemporary fixators which can be placed in a shorter period and ensure a greater stability.

The number of our patients is not sufficient for a reliable correlation analysis, but we can still draw the following more important conclusions from the appliance of the external fixation:

(1) The functional outcome depends on the type of the pelvic injury and the accuracy of the reduction

(2) A dislocation, which is not further posterior than 1 $\mathrm{cm}$, and a symphysis diastase of less than $2.5 \mathrm{~mm}$, result in $65 \%$ excellent and good results in this type of treatment

(3) With type-B (vertically stable) damages, it is only the anterior external stabilization that provides sufficient stability for a definitive treatment (we consider the supraacetabular technique the best for a definitive treatment)

(4) With type-C (vertically instable) injuries, a posterior (interior) fixation in addition is compulsory. It can be applied with a T-plate, U-plate, screws, pelvic traverse, sometimes fixing the wings of the iliac bones to the last L-vertebrae - "technique, various modifications of Galvestone technique, etc. In case that it is impossible - skeleton traction, (the aim is to apply posterior interior fixation by the $10^{\text {th }}$ day)

(5) The affection of the sacroiliac joints and the lumbosacral plexus suggest a poor clinical result.

(6) Definitely, the external fixation has a positive effect during the acute period of the patient's resuscitation and in many cases, with the relevant evidence and if interior fixation is impossible, it can be applied definitively with well satisfactory results.

(7) The results from the treatment of injuries type-B and type-C, examined individually (tables 2, 3), are an eloquent testimony to the severity of the injury and the worse outcome with type-C injuries.

\section{CONCLUSION:}

In conclusion, we would like to present a comparison between the different types of fixations in support to the points stated above. For the evaluation of the results from internal and external fixation in the treatment of our patients, we used Majeed's scheme, modified by us. Its advantage to the other schemes is that it can be used in comparing different treatments (synthesis).

\begin{tabular}{|l|c|c|c|}
\hline Results: & $\begin{array}{c}\text { Total number } \\
\text { of patients: } \\
89\end{array}$ & $\begin{array}{c}\text { External fixation } \\
\text { (external and hybrid fixation only) } \\
65 \text { patients }\end{array}$ & $\begin{array}{c}\text { Internal fixation } \\
\text { (internal only) } \\
24 \text { patients }\end{array}$ \\
\hline Excellent & $47=52.8 \%$ & $34=52.3 \%$ & $13=54.1 \%$ \\
\hline Good & $24=27 \%$ & $17=26.2 \%$ & $7=29.1 \%$ \\
\hline Satisfactory & $10=27 \%$ & $8=12.3 \%$ & $2=8.4 \%$ \\
\hline Poor & $8=9 \%$ & $6=9.2 \%$ & $2=8.4 \%$ \\
\hline
\end{tabular}


The good and excellent results of all treatments of pelvic injuries are $79.8 \%$, and of these $83.2 \%$ are with internal fixation solely, while $78.5 \%$ are with external fixation solely and hybrid fixation. The difference is less than $5 \%$, and having in mind that in many cases the external fixation was irreplaceable, we would like to emphasize again that this method still has its importance and certain place today.

\section{REFERENCES:}

1. Apostolov P, Jivkov M, Tiltfractures of the pelvis - diagnosis and treatment, Bulgarian Journal of Orthopaedics and Traumatology. 2005., vol.42:162-166

2. Riemer BL, Butterfield SL, Diamond DL, et al: Acute mortality associated with injuries to the pelvic ring: The role of early patient mobilization and external fixation. J Trauma 35:671-677, 1993.

3. Egberg HJ, Drajher F, HavemanD, et al. Stabilisierung des beckenrings mit fixateur externe-biomahanische untersuchungen und klinische erfahrungen. Orthopade 1992; 21:363-372

4. Kim WY, Hearn TC, Seleem O, Mahalingam E, Stephen D, Tile M. Effect of pin location on stability of pelvic external fixation. Clin Orthop Relat Res. 1999 Apr; (361):237-44. [PubMed]
5. Bircher MD. Indication and techniques of external fixationof the injured pelvis. Injury. 1996; 27 Suppl 2:B3-19 [PubMed]

6. Ertel W. General assessment and management of the polytrauma patient. In: Tile M, Helfet D, Kellam J. eds. Fractures of the pelvis and acetabulum. $3^{\text {rd }}$ ed. Philadelphia: Lippincott, Williams and Wilkins, 2003:61-79

7. Pohlemann T, Regel G, Bosch U, et al. Notfallbehandlung und komplextrauma. In: Tscherne H, Pohleman T, eds. Becken and acetabulum.Berlin: Springer; 1998: 89116

8. McRae R. Practical fracture treatment. Churchill Livingstone $19943^{\text {rd }}$ ed. 239-242.

9. Solomon LB, Pohl AP, Sukthankar A, Chehade MJ. The subcristal pelvic external fixator: technique, results, and rationale. $J$ Orthop Trauma. 2009 May-Jun;23(5):365369. [doi: 10.1097/BOT.0b013e3181a2aec3 ] [PubMed]

10. Waikakul S; Kojaranon $\mathrm{N}$; Vanadurongwan V, Harnroongroj T. An aiming device for pin fixation at the iliac crest for external fixation in unstable pelvic fracture. Injury. 1998 Dec;29(10): 757-762. [PubMed]

11. Ganz R, Krushell RJ, Jakob RP, Kbffer J. The antishock pelvic clamp. Clin Orthop Relat Res. 1991 Jun; 267:71-78 [PubMed]

12. Buckle R, Browner B, Morandi M. Emergency reduction for pelvic ring disruptions and control of associated hemorrhage using the pelvic stabilizer, Techniques in Orthopaedics Winter 1994; 9(4):258-266.

\author{
Address for correspondence: \\ Pavlin Kirilov Apostolov \\ MBAL "St. Anna"- Varna, Clin. Orthopaedy and Traumatology \\ 100, Tzar Osvoboditel Blvd., 9000 Varna, Bulgaria \\ Bulgaria, Varna, Mladost 142-9-4-194 \\ E-mail: dr_apostolovo@yahoo.com.hk
}

